\title{
REVIEW STUDIES ON APPLICATION OF NANOTECHNOLOGY IN TEXTILES
}

\author{
RADHIKA DAMULURI ${ }^{1}$, KAVITHA KIRAN ${ }^{2} \&$ D.P.CHAKRAVARTHY ${ }^{3}$ \\ ${ }^{l}$ Department of Apparel \&Textile, College of Home Science, Delhi, India \\ ${ }^{2}$ Human Development and Family Studies, College of Home Science, Delhi, India \\ ${ }^{3}$ Organic Chemistry, Director Esavyasa Technologies, Delhi, India
}

\begin{abstract}
The nanotechnology is used for multiple purposes in textile industry. Nanotechnology is applied on textiles to improve properties, such as water repellency, wrinkle resistance, uv-protection and anti-bacterial and anti-static, without altering other properties. The stability of application of nano materials on textiles has a key role in determining the success of nano textiles economically and suitability for environmental safety. The scope of nanotechnology in textiles is reviewed.
\end{abstract}

KEYWORDS: Nanotechnology, Water Repellence, UV-Protection, Anti-Bacterial, Anti-Static \& Wrinkle Resistance

Received: Aug 20, 2017; Accepted: Sep 09, 2017; Published: Oct 28, 2017; Paper Id.: IJTFTDEC20171

\section{INTRODUCTION}

The research done in nanotechnology is finding multiple applications, in vast range of areas. As this technology deals, with special properties of materials, many governments are focusing on research and development in nanotechnology.

Nanotechnology is the branch of technology that deals with manipulation of materials, on an atomic or molecular scale. Nano-particles commonly used in commercial products are in the range of 1 to $100 \mathrm{~nm}$. Nanotechnology can be used to alter the properties of materials, to synthesize and to develop the next generations of improved materials, devices, structures, and systems (PatraJ. K\& S. Gouda, 2013).

\section{NANOTECHNOLOGY IN TEXTILES}

The conventional methods used to impart different properties, to improve quality of fabrics do not give permanent effects and are lost with regular washing and wearing.

Application of nanotechnology in textile industry can impart highly durable properties to fabrics, due to high surface area-to-volume ratio and high surface energy of nano- particles, without altering the texture, feel and breathability of fabrics. (Wong et.al; 2006)

The first work on nanotechnology in textiles was undertaken by Nano-Tex, a subsidiary of the US-based Burlington industries (Russel. E, 2002) Later, more and more textile companies, began to invest in the development of nanotechnology. A variety of novel nanotech textiles are already manufactured at this moment. Areas of nanotechnology applications include sports industry, skincare, space technology and clothing as well as materials 
technology, for better protection in extreme environments. (PatraJ. K\& S. Gouda, 2013)

\section{APPLICATION OF NANOMATERIALS}

Special functions and properties can be imparted to textiles, by adding nanomaterials in the manufacturing and finishing process; these nanomaterials are either integrated into the fiber volume or applied as a coating, onto the textile. (Som, et. al., 2009) The coatings are generally composed of nano-particles, a surfactant, ingredients and a carrier medium. Various methods are used foe coating nanomaterials, such as spraying, transfer printing, washing, rinsing and padding. Padding is the most commonly used method of coating. (Wong et.al; 2006) The nano particles are applied to the fabric, with the help of a padding material under suitable pressure and speed. The fabric will be dried and cured after this procedure.

The application of nanotechnology allows imparting multiple properties, to textiles such as:

Water Repellency: Nano-Tex is the treatment given to improve the water-repellent property of fabric, by creating nano-whiskers that are added, to the fabric to create apeach fuzz effect, without lowering the strength of cotton. Water remains on the top of the whiskers and above the surface of the fabric (Russel. E, 2002; Draper. D, 2003; Kathiervelu S. S, 2003)

Nano-spheres are developed to manufacture water repellent fabrics, by Swiss textile company Scholler. Application of nano-spheres on textiles creates surface structures, with gel -forming additives that repel water and dust particles. We can find similar mechanism in lotus leaves, which repel water drops and prevent dust from getting attached to the surface of the leaves.

Hydrophobic property can be imparted to a cotton fabric, by coating it with a thin nano particulate plasma film, without altering the softness and abrasion resistance (Russel. E, 2002; Wong et.al; 2006)

UV-Blocking: Several researches in the field of nanotechnology are being conducted, to impart uv-blocking properties to textiles Uv-blocking treatment, was given by sol-gel method to cotton fabrics. Sol-gel method forms a thin layer of titanium dioxide on the fabric surface, giving uv-protection property to the fabric. The property is proved to be wash resistant, withstanding repeated launderings. ( $\underline{\text { Xin }}$, J. H, Daoud, W. A.etal., 2004)Apart from titanium dioxide, zinc oxide nano rods of 10 to $50 \mathrm{~nm}$ in length were applied to cotton fabric, to provide UV protection (Wang, R. Het. al.; 2004; Wonge. tal; 2006).

Wrinkle Resistance: To impart wrinkle resistance to fabric, resin is commonly used in conventional methods. However, the limitations of applying resins are decreased in the tensile strength, abrasion resistance, water absorbency and dye-ability, as well as breathability. To overcome these limitations of using resin, some researchers employed nanotitanium dioxide and nano-silica, to improve the wrinkle resistance of cotton and silk, respectively (Wong et.al; 2006; Patra \& S. Gouda, 2013)

Anti Bacterial: For imparting anti-bacterial properties, nano-sized silver (Yeo, S. Y et.al, 2003; Lee. H. J.et.al, 2003), titanium dioxide (Burmiston. N, 2003; Sharman \& Jonathan, 2003; Daoud. W. A. et. al 2004) and zinc oxide (Saito. M, 1993) are used. It was found that, Nano-silver particles have bactericidal and fungicidal effects, and they inhibit the growth of infection, causing bacteria and fungi thus, nano-silver particles are applied to clothing that is worn next to the skin, such as socks and stockings. In addition, nano-silver can be applied to a range of other healthcare products, such as 
dressings for burns, scald, skin donor and recipient sites (Yeo, S. Yet.al, 2003; Athinson. W, 2004; Y. W. H. Wong et. al; 2006).

Anti-Static: Anti-static properties can be imparted to synthetic fabrics, to dissipate static build using nano technology. It was determined that, nano-sized titanium dioxide (Dong. W. G. \& Huang. G. 2003), zinc oxide whiskers (Zhou. Z. W. et.al 2003), nano antimony-doped tin oxide (ATO) (Wu, Y., Chi et.al; 2002), could impart anti-static properties to synthetic fibers. $\mathrm{TiO} 2, \mathrm{ZnO}$ and ATO provide anti-static effects because, they are electrically conductive materials.

\section{STABILITY OF THE NANOMATERIALS IN TEXTILE APPLICATIONS}

Though, application of nanotechnology has multiple benefits to offer, careful measures should be taken to ensure product quality and environmental safety.

Stabilized application of nanomaterials to the fabric surface is very essential, to maintain the functionality and special properties of fabrics and also, to avoid release of nanomaterials into environment, which might cause potential hazards to health.

Stability of nanomaterials in textiles depends on the strength of bond between nanomaterials and textile fibers, the sight of bonding, viz. sheath of the fiber or core of the fiber and abrasion resistance and flexibility.

\section{CONCLUSIONS}

Nanotechnology is growing at a fast pace and it has been introduced in many fields, including the textile industries. Its application can economically extend the value of textiles. Nanotechnology overcomes the limitations of applying conventional methods, to impart certain properties to textile materials. In the next few years, nanotechnology will penetrate into every area of textile industry. However, application of nano materials should generally be tested for safety, with regard to human health and the environment, before they are marketed. In addition, to ways of protecting the environment, the risks posed by nano materials and their use should be studied at an early stage of development, to ensure the safety of the textile products.

\section{REFERENCES}

1. Y. W. H. Wong, C. W. M. Yuen, M. Y. S,Leung, S. K. A. Ku and H. L. I. Lam.,Selected application of nanotechnology in textiles, AUTEX research Journal,2006. Vol 6, no 1; www. autexrj. com/articles/36

2. Russell, E., Nanotechnologies and the shrinking world of textiles, Textile Horizons, 2002. 9/10: p. 7-9.

3. Xin, J.H., Daoud, W.A., and Kong, Y.Y., A New Approach to UV-Blocking Treatment for Cotton Fabrics, Textile Research Journal, 2004. 74: p.97-100.

4. Yeo, S.Y., Lee, H.J., and Jeong, S.H., Preparation of nanocomposite fibers for permanent antibacterial effect, Journal of Materials Science, 2003. 38: p.2143-2147.

5. $\quad$ Draper D., Very little to it, WorldSportsActivewear,2003.19: p.16-17.

6. Kathiervelu, S.S., Applications of nanotechnology in fibre finishing, Synthetic Fibres, 2003. 32: p. 20-22.

7. Burniston, N., Bygott, C., and Stratton, J., Nano Technology Meets Titanium Dioxide, Surface Coatings International Part A, 2004: p.179-814. 
8. Sherman and Jonathan, Nanoparticulate Titanium Dioxide Coatings, and Processes for the Production and Use thereof, Pat. No 736738,2003

9. Saito,M.,Antibacterial,Deodorizing,andUVAbsorbingMaterialsObtainedwithZincOxide(ZnO) Coated Fabrics, Journal of Coated Fabrics, 1993. 23: p.150-164.

10. Daoud, W.A. and Xin, J.H., Low temperature sol-gel processed photo catalytic titania coating, Journal of Sol-Gel Science and Technology, 2004. 29: p.25-29.

11. Wang, R.H., Xin, J.H., Tao, X.M., and Daoud, W.A., ZnO nanorods grown on cotton fabrics at low temperature, Chemical Physics Letters, 2004. 398: p.250-255.

12. Anonymous, Nanotechnologies keep feet healthy, Advance in Textiles Technology, 2003. 3: p. 10-11.

13. Lee, H.J., Yeo, S.Y., and Jeong, S.H., Antibacterial effect of nanosized silver colloidal solution on textile fabrics, Journal of Materials Science, 2003. 38: p.2199-2204.

14. Yeo, S.Y. and Jeong, S.H., Preparation and characterization of polypropylene/silver nanocomposite fibers, Polymer International, 2003. 52: p.1053-1057.

15. Daoud, W.A. and Xin, J.H., Nucleation and growth of anatase crystallites on cotton fabrics at low temperatures, Journal of the American Ceramic Society, 2004. 87: p.953-955.

16. Athinson, W., Hi-ho silver, Industrial Fabric Product Review, 2003. 88: p.12-17.

17. Petra Apel, Dr. Wolfgang Dubbert, Dr. KatrinSchwirn, Brigitte Zietlow uses of nano materials in textiles, Umwelt BundesAmt, 2013. (www.umweltbu)

18. Som, C., Halbeisen, M., and Köhler,A. (2009): Integration von Nanopartikeln in TextilienAbschätzungenzurStabilitätentlang des textilenLebenszyklus.

19. Som,C., Nowack,B., Wick,P., and Krug,H. (2010): Nanomaterialien in Textilien: Umwelt-, Gesundheits- und SicherheitsAspekteFokus: synthetischeNanopartikel. www.empa.ch/nanosafetextiles.

20. Bickel,M. and (2011): Som,C. nano textiles Grundlagen und LeitprinzipienzureffizientenEntwicklungnachhaltigerNanotextilien. www.empa.ch/plugin/template/empa/*/113719

21. J. K. Patra and S, Gouda, Application of nanotechnology in textile engineering: an overview, Academic Journal, 2013. Vol 5, p 104-111. 